\title{
Abordagem sistêmica na Gestão de Design para construção de plataforma habilitante destinada à agricultura orgânica familiar
}

\author{
Systemic approach in the Design Management for construction of enabling \\ plataforms destined of family organic agriculture
}

FIGUEIREDO, Luiz Fernando Gonçalves de; PhD; UFSC

luiz.fernando@ufsc.br

WEBER, Karina Pereira; Doutoranda; UFSC

karinaweber.rs@gmail.com

\section{Resumo}

O trabalho trata sobre a abordagem sistêmica para a criação de ferramentas de gestão de design, destinadas à agricultura orgânica familiar, disponibilizadas por plataformas habilitantes. Utilizouse de questionário e entrevista semi-estruturada destinados aos consumidores, para compreender como o consumo de orgânico tem sido entendido e valorizado. Como parte da abordagem sistêmica, objetivou-se como etapa inicial da pesquisa, iniciar o mapeamento por esse subsistema: consumidores (demanda). A partir dessa compreensão inicial, foi possível perceber algumas fragilidades e falta de divulgação dos valores da agricultura orgânica que não são exploradas pelos próprios agricultores por não adotarem gestão estratégica. Assim, propõe-se a partir do co-design, envolver agricultores da agricultura orgânica familiar no processo de conscientização e promoção do consumo responsável a partir da apropriação do Design como meio de comunicação pedagógica para a inovação social.

Palavras Chave: abordagem sistêmica; plataformas habilitantes; agricultura orgânica familiar.

\begin{abstract}
This paper is about the systemic approach for inserting strategic tools of design management in the family organic agriculture context, provided by enabling plataforms. A questionnaire and semistructured interview were used for consumers, to understand how the consumption of organic has been understood and valued. As part of the systemic approach, the initial goal of the research was to initiate the mapping by this subsystem: consumers (demand). From this initial understanding, it was possible to perceive some fragilities and lack of dissemination of the values of organic agriculture that are not exploited by the farmers themselves for not adopting strategic management. Thus the objective of this research in development is, from the co-design, to involve the farmers of the family organic agriculture in the process of awareness and promotion of the responsible consumption from the appropriation of the design like pedagogical communication for social innovation.
\end{abstract}

Keywords: systemic approach; enabling plataforms; family organic agriculture. 


\section{Introdução}

A abordagem sistêmica na Gestão de Design contribui para o entendimento de um sistema de maneira ampliada e não necessariamente de modo linear. A abordagem sistêmica proporciona compreender a interrelação entre os elementos, ou subsistemas de um sistema (BERTALANFFY, 2015), e trazendo esta abordagem para a Gestão de Design, é possível pensar em processos, serviços e/ou produtos de modo a alcançar projetos de Design orientados à sustentabilidade que sejam mais eficientes. O sistema em questão, da presente pesquisa, trata-se da agricultura orgânica familiar. Para tanto, deve-se considerar a criatividade e as diversas formas de empreendedorismo difusos desse segmento, suas comunidades criativas, que caracterizam novas maneiras de vida na sociedade contemporânea (CEPPI, 2018), como um estilo de vida e modo de produção da cultura "slow". A agricultura orgânica, e a agroecologia, vem buscando novas maneiras de prática, como a agricultura urbana, que tem ocupado espaços urbanos para garantir alimentação saudável e acessível. Nesse contexto, é possível pensar inovações sociais que contribuam na valorização e divulgação desse modo de produção que é mais sustentável do ponto de vista ambiental e social, mas precisa se tornar mais competitivo economicamente.

A partir da compreensão sistêmica da agricultura orgânica familiar, é possível, então, desenvolver soluções, como plataformas habilitantes, que ofereçam suporte por meio de estratégias mais eficientes para tornar este setor mais competitivo ${ }^{1}$, contribuindo para a inovação social - no sentido de mobilizar e conscientizar sobre a importância do consumo de alimentos orgânicos. Como será exposto a seguir, este modelo de agricultura representa uma opção mais plausível para a sustentabilidade no setor alimentício. No entanto, a agricultura orgânica familiar carece de suporte e ferramentas estratégicas de Gestão de Design que ajudem no seu desenvolvimento sustentável. Carece, principalmente, de estratégias de comunicação e informação sobre a produção orgânica, conforme pode-se observar com base no levantamento inicial de dados obtidos com consumidores ${ }^{2}$. Após a análise dos dados, traz-se como proposta o uso de plataformas habilitantes para disponibilizar tais ferramentas que poderão ser apropriadas pelos agricultores, para dar-lhes mais autonomia para agir em prol de um melhor posicionamento e, por conseguinte, contribuir na propagação do consumo consciente e responsável.

As conclusões alcançadas nesta etapa da pesquisa apontam que há ainda desconhecimento acerca dos benefícios do consumo de alimentos e produtos orgânicos por falta de esclarecimentos sobre os mesmos. Ainda, conforme as respostas coletadas dos consumidores abordados, são produtos considerados de difícil acesso e alto custo, o que, em alguns casos, impedem o consumo mesmo que haja a consciência da importância desses produtos. Pode-se, portanto, perceber que existe necessidade de Gestão de Design como ferramenta estratégica para contribuir para uma conexão consciente e afetiva entre agricultores e consumidores. Essa conexão é relevante para engajar agricultor e consumidor em um papel importante de responsabilidade social, contribuindo para inovação social por meio da valorização de um modo de produção alimentícia mais sustentável.

\footnotetext{
${ }^{1}$ Tornar esse setor competitivo significa viabilizar sua inserção de forma mais ampla no mercado local - em princípio , por meio da construção de atributos, tangíveis e intangíveis, de valorização, canais de comunicação, serviços (NETO; TEIXEIRA; MERINO, 2009). Neste aspecto que se compreende o Design como estratégia competitiva para a agricultura orgânica familiar.

2 Os consumidores caracterizam o subsistema foco dessa etapa da pesquisa, como explicitado no tópico 4 deste artigo.
} 


\section{Agricultura orgânica familiar: potencialidade para a inovação social}

Novos estilos de vida vêm surgindo como meios de buscar soluções para problemas contemporâneos que têm a ver com os antagonismos da nossa era. Ao mesmo tempo em que existem discursos sobre a consciência do consumo de alimentos com respeito ao ambiente e demais espécies, vê-se um aumento de uso de agrotóxicos e a prática da má alimentação, onde predomina o consumo de produtos processados e ultraprocessados - produtos alimentícios que podem contribuir para o surgimento de Doenças Crônicas Não-Transmissíveis (LUZ, 2017). A grande indústria alimentícia está alinhada com o mundo dos negócios dos agrotóxicos. Quando se fala em grande indústria alimentícia, o amplo agronegócio, remete-se àquela em que predomina a visão mercantilista do alimento, orientada à quantidade - "mais do mesmo por unidade de tempo", "sob a justificativa de uma possível falta de alimentos" (PINTO, 2016, p. 56). O mundo dos negócios de agrotóxicos no Brasil fatura bilhões anualmente, ao passo que indivíduos podem consumir em média 5,2 kg/ano, dado de 2009, segundo o Instituto Nacional do Câncer José Alencar Gomes da Silva, o INCA ${ }^{3}$ (2015).

Inovações sociais fazem-se necessárias para resolver essas contradições e preservar o bemestar e a qualidade de vida das pessoas e do ambiente. Diante desse cenário, em que a alimentação passou a ser mercadoria e seguiu a lógica desenfreada de exploração de recursos naturais e de animais para alcançar os objetivos de produtividade e lucro, surgiu o movimento "Slow" para romper com a lógica da indústria alimentícia.

O pensamento slow tem influência do movimento Slow Food, fundado em 1986 na Itália, por Carlo Petrini. Com posicionamento oposto ao Fast Food, seu objetivo principal é defender o alimento bom, justo e limpo: "O alimento que comemos deve ter bom sabor; deve ser cultivado de maneira limpa, sem prejudicar nossa saúde, o meio ambiente ou os animais; e os produtores devem receber o que é justo pelo seu trabalho" ${ }^{4}$. Desde a criação do Slow Food, outras vertentes em prol do "movimento lento" surgiram, dentre elas, o Slow Design. Alberto Capatti, Giulio Ceppi, Aldo Colonetti, Ezio Manzini, Anna Meroni e Giacomo Mojoli criaram o manifesto SLOW+DESIGN (CEPPI, 2018) para explicitar a importância da adoção de "slow approach" (abordagem lenta) como forma de resgatar a sensorialidade sustentável. "A sensorialidade sustentável significa hoje desenvolver e construir novos cenários e gerar novas atitudes comportamentais" (CEPPI, 2018, p. 140 , tradução nossa).

Projetos de Design orientados por esse pensamento, buscam inovar em soluções que não gerem obstáculos futuros (FLUSSER, 2007) e se adequem aos princípios da sustentabilidade considerando seus três pilares: ambiental, social e econômico (SCHANDOLARA, 2012). O pensamento slow, orienta a concepção de cenários para promover a inovação social por meio da mudança de comportamentos. A inovação social converge com a ideia do "design humanístico", orientado pelos valores do "ser" e não do "haver", tendo como foco projetos para pensar a sociedade e não o projeto de um produto isoladamente (BISTAGNINO, 2009, p. 14).

O modo de produção "slow" converge com a ideia de descontinuidade sistêmica (MANZINI, 2008), a qual é necessária para reverter o cenário vigente. Atualmente, o crescimento de

\footnotetext{
3 Disponível em: http://www2.inca.gov.br/wps/wcm/connect/comunicacaoinformacao/site/home/namidia/ brasil_lidera_ranking_consumo_agrotoxicos. Acesso em: 25 out 2017.

4 Disponível em: <https://www.slowfoodbrasil.com/slowfood/filosofia/>. Acesso em: 7 mar. 2018.
} 
produção e de consumo é contínuo, o qual se dá sem questionamentos aprofundados dos impactos que geram no ambiente e, muitas vezes, sem questionar a qualidade do que é consumido.

A aceleração de crescimento de produção na grande indústria alimentícia não justifica os impactos negativos ambientais, uma vez que a lógica do mercado gera grande desperdício de alimentos $^{5}$, não tendo como princípio a nutrição e eliminação da fome. A abordagem slow visa a desaceleração desses níveis de consumo ou, pode-se dizer, uma ressignificação do mesmo, tendo o bem-estar como centro das preocupações. Produzir o necessário para o bem-estar.

Nesse âmbito, a agricultura orgânica familiar enquadra-se no conceito slow por estar pautada no modelo tradicional de agricultura e não agredir consideravelmente o ambiente, podendo representar um modelo ecoeficiente ${ }^{6}$ (VEZZOLI, 2010). Ela preza pela produção com baixo impacto ao ambiente, utilizando-se apenas de insumos orgânicos; pelo respeito ao ciclo agrícola natural e os períodos adequados de colheita; preserva a e explora positivamente a biodiversidade, entre outras características que podem ser exploradas para se tornar ainda mais sustentável. Trata-se, portanto, de um modo mais saudável e benéfico para os três pilares básicos da sustentabilidade. $\mathrm{O}$ quadro abaixo demonstra algumas características da agricultura orgânica familiar enquanto "low tech" e "slow" em comparação a agricultura familiar convencional e a grande indústria alimentícia:

Quadro 1 - Modos de agricultura em escala high e low tech explicitando seus tipos de impactos.

\begin{tabular}{|c|c|c|c|}
\hline IMAPCTOS & Grande Agroindústria & $\begin{array}{l}\text { Agricultura Familiar } \\
\text { Convencional }\end{array}$ & Agricultura Orgânica Familiar \\
\hline Sociais & $\begin{array}{l}\text { Lógica da produtividade em } \\
\text { larga escala; não preza a } \\
\text { qualidade do alimento uma } \\
\text { vez que considera o uso de } \\
\text { aditivos químicos e o } \\
\text { resultado são alimentos } \\
\text { processados e } \\
\text { ultraprocessados; contribui } \\
\text { para o êxodo rural } \\
\text { indiretamente, pois "gera } \\
\text { assimetrias no acesso dos } \\
\text { agricultores familiares às } \\
\text { cadeias longas de } \\
\text { mercados de } \\
\text { commodities", ocasionando } \\
\text { em exclusão e redução de } \\
\text { rendas agrícolas (IPEA, } \\
2013, \text { p. 14). }\end{array}$ & $\begin{array}{l}\text { Representa uma } \\
\text { produção com mais } \\
\text { qualidade e segurança } \\
\text { se comparada a da } \\
\text { grande agroindústria, } \\
\text { mas por utilizar de } \\
\text { insumos químicos, não } \\
\text { prioriza a qualidade no } \\
\text { processo e saúde dos } \\
\text { agricultores. } \\
\text { Representa o consumo } \\
\text { de 70\% da alimentação } \\
\text { nacional (MERINO et } \\
\text { al, 2016). }\end{array}$ & $\begin{array}{l}\text { Contribui para a permanência da } \\
\text { família no campo, em seu lugar de } \\
\text { origem e garante a saúde na } \\
\text { produção por não exporem os } \\
\text { agricultores aos malefícios na lida } \\
\text { com agrotóxicos e outros aditivos } \\
\text { químicos; representa um modelo } \\
\text { mais seguro na produção de } \\
\text { alimentos. Caracteriza-se como } \\
\text { comunidade criativa (MANZINI, 2008) } \\
\text { por ser um modo de produção } \\
\text { divergente do predominante, voltada } \\
\text { à qualidade e bem-estar. }\end{array}$ \\
\hline
\end{tabular}

\footnotetext{
${ }^{5}$ Segundo a FAO (Organização das Nações Unidas para a Alimentação e a Agricultura), no Brasil 22 bilhões de calorias são desperdiçadas, o que poderia reduzir de 14 milhões de pessoas afetadas pela fome a 3 milhões. de Disponível em: $<$ http://www.fao.org/americas/noticias/ver/pt/c/239394/>. Acesso em: 28 mar.

6 Entende-se como resultado da produção e consumo economicamente competitivo e socialmente justo e coeso (VEZZOLI, 2010).
} 


\begin{tabular}{|c|c|c|c|}
\hline Ambientais & $\begin{array}{l}\text { Contribui para a } \\
\text { deterioração ambiental por } \\
\text { utilizar mais recursos } \\
\text { naturais no processo } \\
\text { industrial ,além de fazer } \\
\text { uso de aditivos químicos e } \\
\text { transgênicos para acelerar } \\
\text { a produção de alimentos. }\end{array}$ & $\begin{array}{l}\text { Por se tratar de } \\
\text { produção resultante } \\
\text { de uma família, não se } \\
\text { trata de um volume } \\
\text { em grandes escalas, } \\
\text { explorando menos o } \\
\text { solo, mas por } \\
\text { utilizarem insumos } \\
\text { químicos, como } \\
\text { agrotóxicos, poluem e } \\
\text { acumulam resíduos no } \\
\text { ambiente. }\end{array}$ & $\begin{array}{l}\text { Recupera o solo muitas vezes } \\
\text { deteriorado pelo uso de substâncias } \\
\text { nocivas de outros modelos de } \\
\text { produção; valoriza a biodiversidade, } \\
\text { preservando a espécie de sementes } \\
\text { locais uma vez que não utiliza } \\
\text { sementes transgênicas; a base de } \\
\text { cultivo se dá com pouco ou nenhum } \\
\text { uso de maquinário, utiliza menos } \\
\text { recursos naturais para manutenção } \\
\text { do sistema. }\end{array}$ \\
\hline \multirow[t]{2}{*}{ Econômicos } & $\begin{array}{l}\text { Contribui para a } \\
\text { desigualdade social, } \\
\text { embora represente um } \\
\text { percentual importante do } \\
\text { PIB do país. No entanto, } \\
\text { não pratica a distribuição } \\
\text { justa de riquezas. }\end{array}$ & $\begin{array}{l}\text { Gera renda e emprego } \\
\text { na área rural, } \\
\text { reduzindo a pobreza, } \\
\text { favorecendo o } \\
\text { desenvolvimento local. }\end{array}$ & $\begin{array}{l}\text { Depende de incentivos } \\
\text { governamentais para } \\
\text { desenvolvimento; desvantagem em } \\
\text { relação à agricultura convencional, } \\
\text { pois possui o encargo de pagar pela } \\
\text { certificação de produção orgânica } \\
\text { que onera ainda mais o valor final do } \\
\text { produto; pauta-se na economia } \\
\text { responsável e criativa. }\end{array}$ \\
\hline & $\begin{array}{l}\text { HIGH TECH } \\
\text { INSUSTENTÁVEL }\end{array}$ & & $\begin{array}{l}\text { LOW TECH } \\
\text { SUSTENTÁVEL }\end{array}$ \\
\hline
\end{tabular}

Fonte: produzido pelos autores (2018).

A produção de orgânicos no país vem crescendo em média 25 a $30 \%$ ao ano ${ }^{7}$, sendo o país que mais cresce nesse setor. No entanto, ainda são apenas cerca de 940 mil hectares brasileiros destinados à produção orgânica, em comparação a 240 milhões de hectares destinados à produção convencional. Apesar de a agricultura orgânica familiar representar minoria, os dados de crescimento anual indicam que a consciência por parte dos produtores sobre os danos causados pelo uso de agrotóxicos e aditivos químicos vem aumentando. Todavia, essas pessoas, que no Brasil são representadas pela agricultura familiar, optam, em maioria, pela produção orgânica apenas após terem suas saúdes comprometidas pela lida com agrotóxicos e aditivos químicos. 0 contato corporal com os venenos é o mal mais direto e evidente, sofrido pelos agricultores, principalmente, mas eles se propagam das mais diversas formas, como: pelo ar e pela água.

O Design já tem sido aplicado no contexto da agricultura familiar e da agricultura orgânica familiar para contribuir com melhorias na comunicação visual e estratégica dos produtos. As inserções do Design têm se dado para orientar algumas comunidades de agricultores familiares em termos de posicionamento e estratégias. Essas orientações objetivam facilitar a competição dessas comunidades no mercado alimentício, divulgando os valores dos produtos locais, oriundos desse modelo de produção como um diferencial representado pela identidade socioambiental. Pesquisas como as apresentadas por Merino et al. (2016), Krucken (2009) Merino; Merino e

\footnotetext{
${ }^{7}$ Segundo Ming Liu, diretor do Organics Brasil e do ORGANIS, Conselho Nacional da Produção Orgânica e Sustentável Disponível em: http://economia.estadao.com.br/noticias/releases-ae,producao-de-organicos-no-brasil-cresce-eempresas-investem-na-biofach-2017,70001665611/. Acesso em: 21 out 2017.
} 
Figueiredo (2007), entre outras, mostram resultados positivos da inserção do design nessas comunidades.

Nesse mesmo âmbito da alimentação, pode-se mencionar a linha de pesquisa Food Design ${ }^{8}$ para a inovação social, a qual tem como foco desenvolver pesquisas relacionadas à qualidade e desenvolvimento sustentável no setor alimentício. A proposta deste artigo converge com a abordagem dessa linha de pesquisa, pois busca a inovação social a partir do desenvolvimento inovador da agricultura orgânica familiar para alcançar competitividade no mercado.

Após introduzir o contexto da agricultura orgânica familiar como caminho de desenvolvimento e produção de alimentos como modelo mais sustentável, parte-se para a discussão sobre o uso de plataformas habilitantes como meio possível de levar ferramentas de gestão de design ao setor da agricultura orgânica familiar. Posteriormente, expõem-se os resultados obtidos em etapa inicial de coleta de dados com consumidores. A partir da análise dos dados coletados, propõem-se o uso de plataformas habilitantes como meio de empoderar os agricultores com ferramentas que lhes permitam: pensar estrategicamente o negócio e pensar ações para valorização e conscientização sobre o consumo de alimentos e produtos orgânicos.

\section{Plataformas habilitantes para inovação social, sustentabilidade competitividade na agricultura orgânica familiar}

As plataformas habilitantes (MANZINI, 2008) podem proporcionar a inovação de sistemas, que por sua vez, podem ocasionar a inovação social. Por meio da inovação de sistemas é possível alcançar a inovação social, a qual está diretamente relacionada com pensar novas formas de agir, fazer, saber, organizar e envolver os stakeholders no processo de mudança em busca da ecoeficiência. Considerando sobretudo que a inovação social transcende a solução de um problema específico, ela provoca uma mudança social, uma mudança de comportamento consistente (CIPOLLA, SERPA, AFONSO, 2017).

Uma das premissas da inovação social é de que partam de comunidades criativas, dos indivíduos que se organizam por interesses comuns, e não como resultado de uma emergência de mercado. Nesse sentido, para transformar a realidade brasileira em que existem interesses políticos divergentes ${ }^{910}$, é preciso que algo seja feito em prol dos consumidores, para que estes tenham as informações e instruções corretas, que de fato informem o que é produção orgânica e por que ela é a melhor alternativa e que, ao mesmo tempo, preze-se pela qualidade de vida dos produtores. Touraine (2011 apud OLIVEIRA; FREIRE; FRANZATO, 2015) salienta a importância da ação social por parte dos próprios cidadãos. Estes, segundo ele, precisam estar engajados e assumirem responsabilidades sociais para reverter os conflitos atuais nas esferas sociais e

8 Esta é uma das vertentes pesquisadas pela rede Design for Social Innovation and Sustainability (DESIS): http://www.desisnetwork.org/. Acesso em: 21 out 2017. Essa rede contribui com pesquisas que atrelam o design à inovação social para buscar a transformação nos modos de vida.

9 Podemos citar como exemplos a PL 6299/02, proposta pela bancada ruralista que visa mudar o termo "agrotóxicos" já conhecido pela população para "defensivos fitossanitários" com intuito de causar ainda mais confusão e desconhecimento, além de querer flexibilizar a Lei de Agrotóxicos vigente no país para ampliar o uso dos mesmos, ao mesmo tempo em que Ministério da Saúde, INCA e demais órgãos e instituições com interesses orientados à saúde da população, lutam pela restrição do uso de agrotóxicos.

10 A PL 6299/02 pode ser lida na íntegra pelo site: http://www.camara.gov.br/proposicoesWeb/fichadetramitacao?idProposicao=46249. Acesso em: 25 out 2017. 
econômicas. Ou seja, os cidadãos precisam tomar a frente das ações para promover as transformações sociais e não mais esperar unicamente pelos órgãos governamentais.

Para tanto, envolver os próprios agricultores familiares da produção orgânica nessa tarefa de educação e conscientização dos consumidores parece algo possível por meio do co-design e por meio de competências no uso de ferramentas estratégicas em Gestão de Design. Para isso, é preciso sensibilizá-los sobre a importância dos seus papéis em comunicar e divulgar a agricultura orgânica, como também é necessário instruí-los sobre como fazer isto. Um meio de instruí-los pode ser a partir de uma plataforma habilitante.

As plataformas habilitantes podem oferecer soluções habilitantes, kits de ferramentas (MAZINI, 2017) e aportes que os auxiliem na visualização sistêmica para agirem de modo a fortalecer os negócios com postura competitiva. Assim, o designer é capaz de se inserir na comunidade, compreendê-la e propor melhorias em aspectos estratégicos, táticos e operacionais (MOZOTA, 2011) que visem a valorização cultural, local e dos produtos. As plataformas habilitantes tratam-se de intervenções estruturadas capazes de "facilitar a comunicação entre os seus membros, o acesso de pessoas às comunidades, tornar mais fluído e fácil o desenvolvimento dos processos de inovação social decorrentes" (OLIVEIRA; FREIRE; FRANZATO, 2015). Elas buscam propor soluções habilitantes que "fornecem o instrumental cognitivo, técnico e organizacional que amplia a capacidade das pessoas de chegar a um resultado de valor para elas" (MANZINI, 2017, p. 186). Essas plataformas podem ser de diversos tipos e formatos, tanto online, em rede, como por meio de sites, redes sociais, fóruns, aplicativos, quanto materiais impressos, encontros, workshops, etc. A consolidação dessa plataforma adequa-se à necessidade de cada comunidade e do modo como será possível escalonar para outras comunidades do mesmo tipo, pois segundo Manzini (2008) esta é uma característica sustentável das plataformas habilitantes, que elas possam se multiplicar a demais localidades amplificando suas potencialidades.

Para compreender de forma ampla e contemplando todos os aspectos relevantes para proporcionar mais competitividade no setor da agricultura orgânica familiar e conscientização nas pessoas sobre o que consomem, propõe-se a abordagem sistêmica na Gestão de Design. Pois, possibilita articular e coordenar os recursos e saberes existentes dos agricultores orgânicos familiares a fim de orientá-los, proporcionando novos conhecimentos e oportunidades para desenvolvimento e aprimoramento das atividades, das relações entre atores e nos modos como estão divulgando a agricultura orgânica. Assim, torna-se pertinente abordar a Gestão de Design de modo sistêmico para melhor compreender as relações e articulações possíveis desse sistema, considerando questões sociais, ambientais, políticas e econômicas orientado à ecoeficiente.

\section{Abordagem sistêmica na Gestão de Design}

De acordo com Bistagnino (2009, p. 20): "a abordagem sistêmica é o caminho utilizado para que, por meio dela, seja possível afrontar os problemas por diversos ângulos". A Gestão de Design pode ser entendida a partir de três níveis: estratégico, tático e o operacional (MOZOTA, 2011), explicadas na Figura 1. 
Figura 1 - Características de cada nível da Gestão de Design

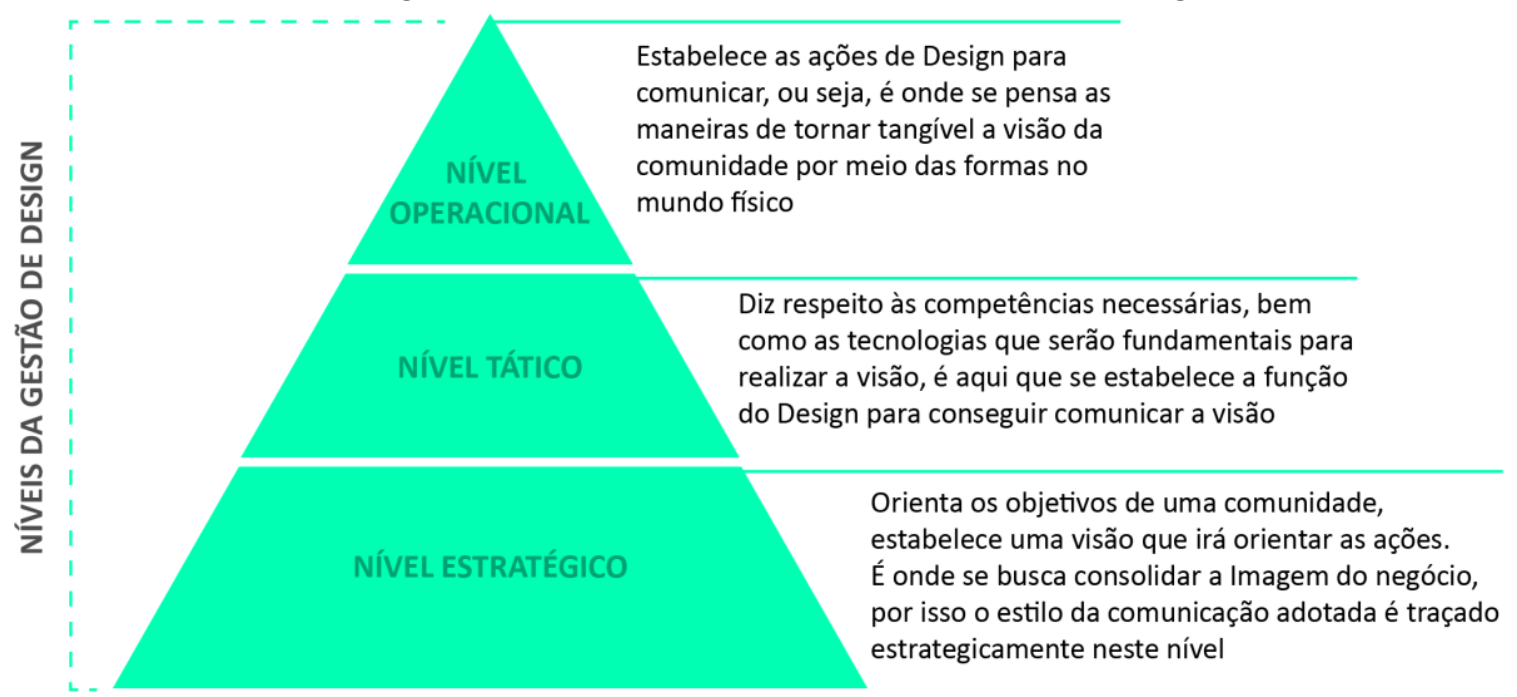

Fonte: Elaborado pelos autores (2018) com base em Martins e Merino (2011).

Para que sejam propostas soluções estratégicas, táticas e operacionais ao objetivo da pesquisa, é preciso ter conhecimento aprofundado sobre o sistema de produção orgânica no país e na região e sobre sistemas de gestão de design. Assim, a abordagem sistêmica na Gestão de Design contribui para uma visão do todo, considerando as relações das partes e articulações do sistema, oportunizando traçar orientações aos agricultores sobre possíveis ações em cada um dos níveis para melhorar seus negócios em termos de informação, valorização e divulgação desse setor.

A abordagem sistêmica na Gestão de Design aplicada a essa comunidade, poderá explorar o Design como ferramenta estratégica para tornar o sistema mais eficiente, funcional e atrativo esteticamente, exaltando qualidades e valores e construindo uma identidade local (MARTINS, MERINO, 2011), podendo promover, ainda, o desenvolvimento local e da comunidade (ROSA, 2013) direcionando melhorias no sistema de produção já adotado.

Para elucidar, exemplifica-se na Figura 2 com alguns objetivos para com a inserção da Gestão de Design na agricultura orgânica familiar que se acredita serem viáveis a partir de boas estratégias: 
Figura 2 - Aplicação dos níveis da Gestão de Design na Agricultura Orgânica Familiar

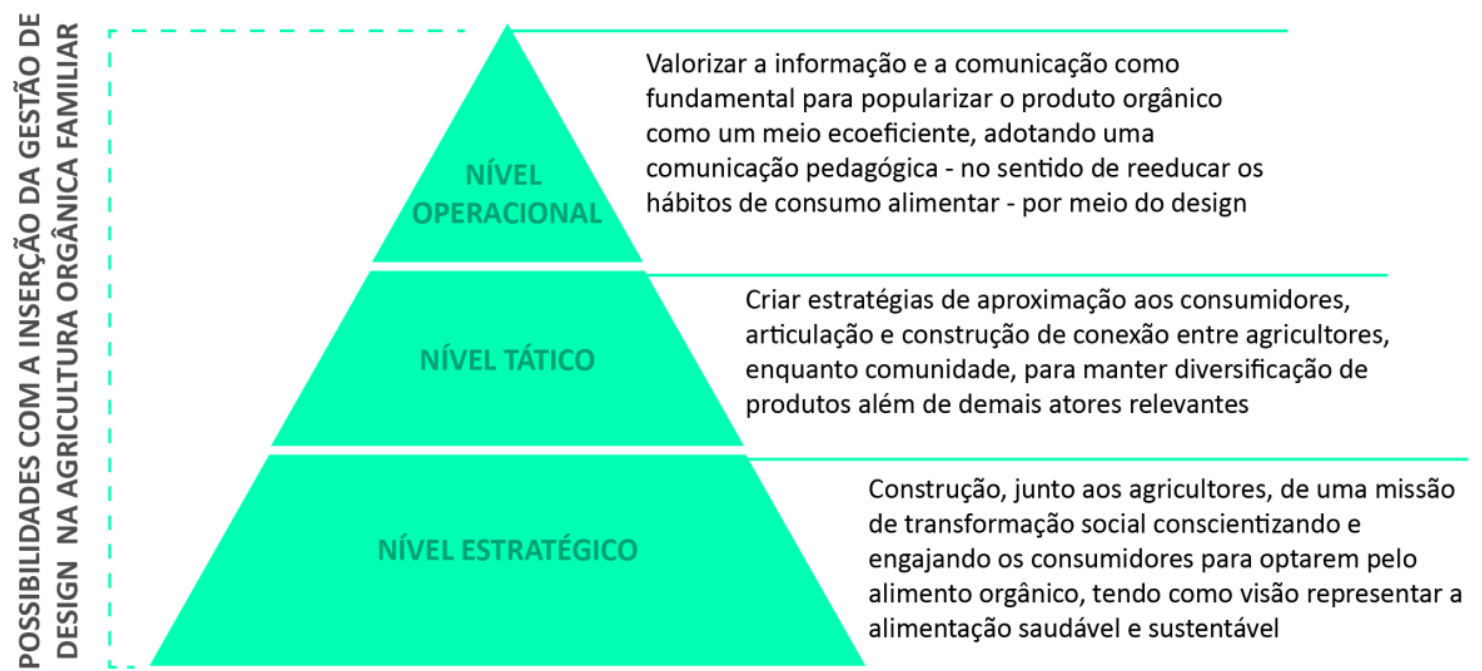

Fonte: Elaborado pelos autores (2018).

Outro ponto possível de ser explorado pela comunicação, é o fato da agricultura orgânica contribuir na preservação de sementes locais e valorização de alimentos locais e regionais que representam a identidade do alimento e da comida brasileira, como elemento cultural (MACIEL, 2005). Algo que tem se perdido com o uso e proliferação de sementes transgênicas.

O Design pode contribuir de forma estratégica para explicitar todo esse diferencial da agricultura orgânica. Assim, vê-se que os agricultores desse setor carecem de competências para gestão estratégica, e elas parecem fundamentais no contexto atual em que a agricultura orgânica é um caminho para a sustentabilidade. A partir do exposto, o objetivo dessa etapa da pesquisa foi entender, como primeiro mapeamento, o que as pessoas (consumidores e possíveis consumidores) compreendem sobre a agricultura orgânica e se há relação da mesma com alimentação de qualidade. Na Figura 3 são representados os principais pontos (subsistemas) do sistema da agricultura orgânica familiar que devem ser compreendidos para pensar a criação da plataforma habilitante. 

habilitante

Figura 3 - Diagrama inspirado nos círculos da Arquitetura de Informação adaptado à criação de plataforma

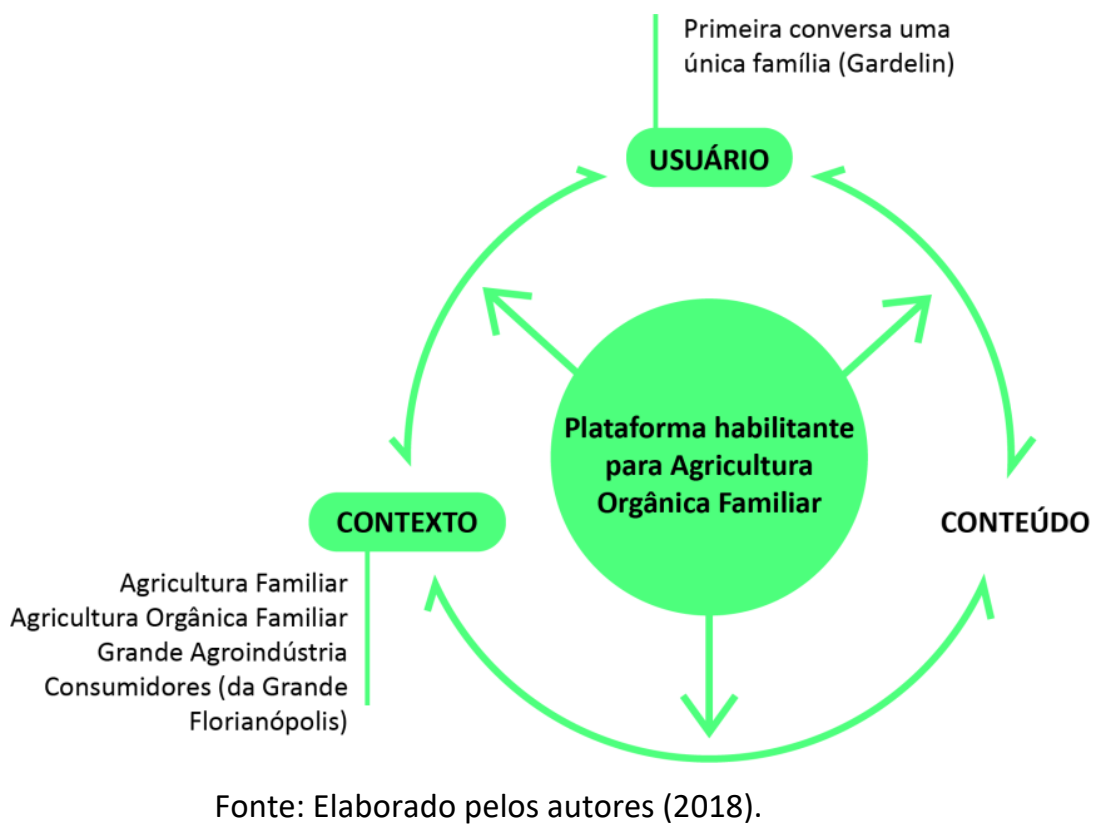

Assim, o artigo apresenta os levantamentos até o momento quanto aos pontos em destaque na figura: usuário e alguns aspectos do contexto da Agricultura Orgânica Familiar no país. 0 elemento 'conteúdo' será desenvolvido até o final da pesquisa e será o resultado apresentado pela plataforma a ser desenvolvida.

\section{Procedimentos metodológicos}

A região da grande Florianópolis representa a delimitação da pesquisa em termos de sujeitos envolvidos, ou seja, os consumidores e possíveis consumidores e os agricultores pesquisados são dessa região, a mesma região de origem dos autores, considerando a viabilidade futura de replicação em outros contextos. Como embasamento para pensar a plataforma habilitante, buscou-se o contexto da agricultura orgânica a nível nacional, ainda que existam, até o momento, leis estaduais e municipais que regulam as produções locais, que também foram consideradas.

Assim, esta etapa de estudo dividiu-se em: pesquisa bibliográfica para entender o contexto da agricultura orgânica nacional e regional, e procedimentos técnicos como questionário misto, para levantamento inicial, e, posteriormente, entrevistas semi-estruturadas com o público-alvo. Após análise do questionário surgiu a necessidade de compreender se o consumo de alimentos orgânicos estava relacionado ao conceito de qualidade alimentícia a partir de entrevistas.

Quadro 1 - Apresentação dos Dados coletados com procedimentos técnicos

\begin{tabular}{llll}
\hline $\begin{array}{l}\text { Procedimento } \\
\text { utilizado }\end{array}$ & Total de respondentes & Faixa etária & Entendimento principal \\
\hline $\begin{array}{l}\text { Questionário misto } \\
\text { online, divulgado homens } \\
\text { apenas no Facebook da }\end{array}$ & $\begin{array}{l}92 \text { entre mulheres e } \\
\text { home-60 anos }\end{array}$ & $\begin{array}{l}\text { Respondentes não consomem orgânicos por } \\
\text { serem mais caros e pela dificuldade de } \\
\text { encontrá-los, embora considerem-no }\end{array}$
\end{tabular}



ou relevante esse tipo de alimento ao mesmo tempo que não sabem o que são agrotóxicos ou consideram-no um mal necessário, crendo que alimento orgânico não dê conta de alimentar a população

Entrevista semi- 16, entre mulheres e 21-50 anos estrutura nas cidade de homens

Florianópolis e São

José, Santa Catarina
Alimentação de qualidade foi atrelada a uma alimentação equilibrada com baixo consumo de industrializados; $80 \%$ não confiam nos alimentos e produtos orgânicos; 12,5\% acreditam que é estratégia de marketing a indicação de orgânico; $12,5 \%$ mencionaram a própria falta de consciência e de hábito em consumir orgânicos; apenas 6,25\% associou a alimentação de qualidade ao consumo de alimentos orgânicos; aqui também apareceram respostas de que o uso de agrotóxicos é um "mal necessário" para dar conta da alimentação da população, $100 \%$ mencionaram que o uso de agrotóxico pode ser prejudicial à saúde e que falta controle no uso e educação sobre como deve ser usado, $18,5 \%$ comentaram ser interessante divulgar e criar valor aos produtos locais, sendo informações pouco exploradas em rótulos e embalagens.

Fonte: elaborado pelos autores (2018).

Realizou-se ainda, uma breve entrevista com um membro de uma família produtora de orgânicos da região (feirante nas localidades de Coqueiros, Florianópolis, e Pedra Branca, Palhoça) para perceber as necessidades da inserção do Design, onde foi entendido que não há investimento em marketing e Design para divulgação dos produtos e das feiras onde atuam, bem como inexiste auxílios que os orientem em termos de ampliação dos negócios para maior rentabilidade. Os agricultores dessa realidade, por exemplo, ficam condicionados prioritariamente às associações das quais fazem parte. Eles se identificam como cooperadores de associações em vez de adotar uma postura administrativa e empreendedora do próprio negócio. Inexiste engajamento competitivo. Segundo o entrevistado, acreditam no boca-a-boca como divulgação da feira (canal mais vantajoso de venda em termos de receita líquida), e contam com um crescimento a médio e longo prazo de popularização por via desse canal pessoal. Parte da pouca expansão do negócio, se dá, também, por falta de instrução sobre como expandi-lo sem descaracterizar o registro de agricultor, comentou o entrevistado.

\section{Percepção dos Consumidores e Necessidades de (Re)Educação sobre Alimentos de Qualidade e Alimentação Slow}

De $100 \%$ dos entrevistados, $93,75 \%$ demonstrou falta de conhecimento sobre o que é alimento orgânico. Cerca de $50 \%$ dos entrevistados relacionaram orgânicos diretamente a saladas, verduras, legumes e frutas como alimento orgânico. Não relacionam que o uso de agrotóxicos impacta na produção de farinhas e grãos, por exemplo. Apenas 6,25\% mencionaram buscar por 
grãos que sejam orgânicos, mas ponderaram que não é fácil encontrá-los, além de mencionarem ser a categoria com mais diferença de valor quando comparado ao convencional, o que os levam a consumir basicamente verduras e frutas orgânicas.

O conhecimento sobre orgânicos está inter-relacionado ao conhecimento sobre agrotóxicos, devido aos interesse sociopolíticos que influenciam no desenvolvimento de cada tipo de produção. Se houvesse conhecimento sobre agrotóxicos, acredita-se que ter-se-ia obtido respostas mais claras que iriam além de: "algo que faz mal à saúde". Percebe-se uma falta de clareza e desconhecimento, percebido pelos próprios respondentes, pois comentaram que ingerem algo que desconhecem.

Outra resposta obtida em uma das entrevistas, mencionou que optar pelas sementes transgênicas (geneticamente modificadas) seria um caminho para evitar o uso de agrotóxicos, uma vez que, segundo o respondente, elas não dependem do uso de agrotóxicos para o cultivo, No entanto, o processo de cultivo, na prática, é o oposto disso. Segundo o INCA (Instituto Nacional de Câncer), em seu posicionamento sobre o uso de agrotóxicos, foi justamente a liberação do uso de sementes transgênicas que colocou o Brasil no topo do ranking de consumo de agrotóxicos, pois as sementes exigem o uso de quantidades grandes destes produtos ${ }^{11}$. A relação entre sementes geneticamente modificadas e consumo de agrotóxicos tem a ver com o aumento anual de faturamento nesse setor. De 2001 para 2011 a venda subiu para 6,5 bilhões de dólares, atingindo 8,5 bilhões em vendas (INCA, 2016).

O uso de agrotóxicos impacta todas as fontes de recursos vitais e por isso devem ser combatidos (INCA, 2015). De acordo com o INCA (2015), alimento in natura, solo, água, ar, leite materno e carne são contaminados por esses produtos. Basicamente tudo do que precisamos para estarmos vivos e nutridos. Portanto, nota-se a emergência em melhor informar a sociedade dos reais malefícios que estes produtos estão trazendo para a vida dos brasileiros.

Respostas como: "entende-se que seja necessário o uso de agrotóxicos para produzir alimentos para toda a população" não podem ser aceitas e nem devem ser críveis, e esta resposta foi dada por, pelo menos, $70 \%$ dos entrevistados. Percebe-se a necessidade de gerar um senso crítico no consumidor: até que ponto a escala industrial condiz com a real necessidade de produção desses alimentos? Quanto do que é produzido é desperdiçado antes mesmo de chegar às casas das pessoas que precisam e carecem de alimentação? A comunicação pedagógica, mencionada neste artigo, condiz com estes questionamentos. A produção orgânica com a adoção técnicas de adubo e fertilizantes naturais torna o solo cada vez mais rico e próprio ao cultivo. São distorções da indústria dos agrotóxicos e de sementes transgênicas que causa confusão e desinformam os consumidores, fazendo-os crer que este seja um meio necessário de produção de alimentos para suprir a demanda mundial. Quando, na verdade, este tipo de produção gera toneladas de desperdícios de alimentos e, logo, de recursos naturais como a água para serem produzidos e não serem consumidos.

O INCA defende como modelo agrícola o da agroecologia e da produção orgânica, pois:

Este modelo otimiza a integração entre capacidade produtiva, uso e conservação da biodiversidade e dos demais recursos naturais essenciais à vida. Além de ser uma alternativa para a produção de alimentos livres de agrotóxicos, tem como base o

\footnotetext{
11 Disponível em: http://www1.inca.gov.br/inca/Arquivos/comunicacao/posicionamento_do_inca_ sobre_os_agrotoxicos_06_abr_15.pdf. Acesso em: 27 out 2017.
} 
equilíbrio ecológico, a eficiência econômica e a justiça social, fortalecendo agricultores e protegendo o meio ambiente e a sociedade (2015, p. 5).

O Guia Alimentar da População Brasileira (GAPB) também considera como caminho para alimentação saudável e de qualidade o consumo de alimentos orgânicos. De acordo com o GAPB (2014 apud LUZ, 2017) "é fundamental que ações de educação alimentar e nutricional sejam desenvolvidas por diversos setores, incluindo saúde, educação, desenvolvimento social, desenvolvimento agrário e habitação". Pensa-se que essa educação da população também possa partir dos próprios agricultores familiares da produção orgânica. Se eles forem capacitados a pensar como gestores do negócio, pensando estratégias de comunicação, design e de missão do negócio, eles podem contribuir com um importante papel de informar a sociedade sobre os benefícios dos alimentos orgânicos. Entende-se como preocupante pensar que pessoas sejam levadas a crer que um alimento orgânico é fruto de marketing, enquanto os produtos ultraprocessados são consumidos mais tranquilamente, quando, segundo Luz (2017) estes é que se utilizam do marketing para serem consumidos.

\section{Considerações finais}

Essa foi uma etapa de prospecção da pesquisa para realizar um breve mapeamento sobre a percepção do alimento orgânico e o comportamento do consumidor com relação a esse tipo de produção. Essa etapa possibilitou identificar oportunidades que a agricultura orgânica familiar da região da grande Florianópolis pode explorar como estratégia para tentar construir uma comunicação mais efetiva e conscientizadora para com os consumidores. O consumidor é um dos atores fundamentais desse sistema, uma vez que é preciso haver demanda e motivação dos mesmos para que esse setor se sustente economicamente.

Os dados coletados, a partir das respostas dos consumidores, mesmo que em fase inicial da pesquisa, demonstraram a pertinência de projetar uma plataforma habilitante capaz de fornecer ferramentas de gestão estratégica e conteúdos úteis e que possam ser apropriados pelos agricultores familiares da produção orgânica. O processo de criação dessa plataforma pauta-se no co-design, levando informações que contextualizem a realidade do consumidor, que, às vezes, é desconhecida pelos agricultores e, a partir disso, sensibilize e os motive a agir para melhor divulgar esse modo de produção. A partir dos dados obtidos, foi possível evidenciar possibilidades de estratégias nos três níveis da Gestão de Design. Essas estratégias podem contribuir para tornar o setor de orgânicos mais competitivo, visível e valorizado.

Entende-se que a plataforma habilitante pode levar noções sobre como desempenhar as estratégias nos três níveis de gestão, auxiliando na execução das mesmas, pois a grande dificuldade em se tornar competitivo é, mais do que explorar diferenciais e vantagens mais convincentes, saber fazê-lo melhor que seus concorrentes (MERINO; MARTINS, 2011). Conforme o observado, por parte dos consumidores existe um desconhecimento sobre os benefícios e vantagens em consumir um produto orgânico que ainda é visto apenas sob o aspecto de custos; por parte da família de produtores entrevistada, não existe preocupação em divulgar e comunicar sobre o modo de produção. Assim, não está sendo explorado o caráter comunicativo que, atualmente, é relevante em um cenário em que é mais acessível um alimento produzido com agrotóxicos. Vê-se, portanto, uma necessidade de intervenção do Design para melhor posicionar e levar informações aos consumidores.

Para além de um posicionamento de mercado, entende-se que o Design precisa estar 
próximo de projetos que estejam alinhados à sustentabilidade, assim como contribuir para uma percepção esclarecedora sobre a agricultura orgânica familiar. A inovação social traz ao Design um olhar crítico sobre como é possível construir um mundo mais consciente, e é preciso levar essa área a outras áreas que ainda careçam de seus conhecimentos e que tenham, por si mesmas, enquanto comunidades criativas, um papel importante para um mundo melhor.

Mais do que criar uma ferramenta para auxiliar a competitividade do setor, trata-se de sensibilizar e educar os agricultores a adotar uma visão sistêmica sobre suas próprias atividades. Acredita-se que por meio dessa conscientização, conceder autonomia seja possível. Quando se fala em autonomia espera-se não só servir-lhes com ferramentas, mas, mais do que isso, introduzir uma nova maneira de encarar a própria atividade e suas interrelações no espaço social. As ferramentas seriam um meio para, a partir dessa nova concepção da atividade e dos papéis de cada ator desse sistema, poder agir para alcançar os objetivos de difundir a agricultura orgânica como um processo slow necessário para alcançar melhores qualidades e hábitos de vida.

\section{Referências}

ANDRADE, A.L.; SELEME, A.; RODRIGUES, L. H.; SOUTO, R. Pensamento Sistêmico: caderno de campo: o desafio da mudança sustentada nas organizações e na sociedade. Porto Alegre: Bookman, 2006.

BERTALANFFY, Ludwig von. Teoria geral dos sistemas: fundamentos, desenvolvimento e aplicações. 8. ed. Petrópolis: Vozes, 2015.

BISTAGNINO, Luigi. Design sistêmico: uma abordagem interdisciplinar para a inovação. In: MORAES, Dijon de; KRUCKEN, Lia.(org.). Design e sustentabilidade. Barbacena: EdUEMG, 2009. v. 2. p. 13-29.

CIPOLLA, Carla; SERPA; Bibiana; AFONSO, Rita. Design for social innovation between university and the broader society: a mutual learning process. Disponível em: http://www.desisnetwork.org/wp-content/uploads/2017/08/09-Cipolla-Serpa-Afonso _SBDS_ISSD_17final.pdf. Acesso em: 15 set 2017.

INCA. Posicionamento do instituto nacional de câncer josé alencar gomes da silva acerca dos agrotóxicos. Disponível em: <http://www1.inca.gov.br/inca/Arquivos/comunicacao/posicionamento_do_inca_sobre_os_agrot oxicos_06_abr_15.pdf>. Acesso em: 25 out. 2017.

KRUCKEN, Lia. Design e território: valorização de identidade e produtos locais.

São Paulo: Studio Nobel, 2009.

LUZ, Laís Tamiris das Neves Felizardo da. Proposta de intervenção didática acerca da rotulagem nutricional dos alimentos envolvendo o conceito de concentração comum a fim de conscientizar alunos do ensino médio sobre os malefícios causados pela má alimentação. São José: [s. n.], 2017. $152 \mathrm{f}$.

MACIEL, Maria E. Olhares antropológicos sobre a alimentação: identidade cultural e alimentação. In: CANESQUI, AM., and GARCIA, RWD., orgs. Antropologia e nutrição: um diálogo possível [online]. Rio de Janeiro: Editora FIOCRUZ, 2005. 306 p. Antropologia e Saúde collection. P. 59-66.

MANZINI, Ezio. Design para inovação social e sustentabilidade: comunidades criativas, 
organizações colaborativas e novas redes projetuais. Rio de Janeiro: E-Papers, 2008.

MANZINI, Ezio. Design, quando todos fazem design: uma introdução do design para a inovação social. / Ezio Manzini; tradução Luzia Araújo. São Leopoldo, RS: Ed. UNISINOS, 2017.

MARTINS, Rosane F.F.; MERINO, Eugenio A. D. A gestão do design como estratégia organizacional. 2.ed. Londrina: Eduel; Rio de Janeiro: Rio Books, 2011.

MERINO, E.; MERINO, G., FIGUEIREDO, L. F.G. Design Valorizando produtos da agricultura familiar - Hermes de Ré. Florianópolis: EPAGRI, 2007. 109p.

MERINO, G., et al. Design e agricultura familiar: ações de valorização e identificação em Santa Catarina. In: 12 P\&D Design, 2016. Belo Horizonte. Anais... São Paulo: Blucher, 2016, novembro 2016 vol. 2 num. 9. p. 1659-1670.

MOZOTA, B. B. de. Gestão do Design: usando o design para construir valor na marca e inovação corporativa. Porto Alegre: Bookman, 2011.

NETO, Alber; TEIXEIRA, Julio M.; MERINO, Eugenio. A contribuição da Gestão de Design na valorização de grupos produtivos de pequeno porte vinculados a origem. In 50 Congresso Internacional de Pesquisa em Design, Bauru, Brasil. 2009.

OLIVEIRA, C. M. M.; FREIRE, K. M.; FRANZATO, C. A inovação social orientada pelo design: perspectivas para criação de uma plataforma habilitante. In: 5옹 Simpósio de Design Sustentável. p. 434-444. Rio de Janeiro. 2015.

PINTO, Laura de Souza Cota Carvalho Silva. DESIGN RELACIONAL: uma possibilidade para a conexão, viabilização e valorização de produtos alimentícios artesanais no Brasil. 2016. 207 f. Tese (Doutorado) - Curso de Design, Programa de Pós-graduação, Puc-rio, Rio de Janeiro, 2016. Disponível em: <https://www.maxwell.vrac.puc-rio.br/27463/27463.PDF>. Acesso em: 28 fev. 2018.

ROSA, Valéria I. A Compreensão da Gestão de Design: Estudo de Caso Cooperativa COLIMAR. 2013. 144 p. Dissertação (mestrado) - Universidade Federal de Santa Catarina, Centro de Comunicação e Expressão. Programa de Pós-Graduação em Design e Expressão Gráfica. UFSC, Florianópolis, 2013.

SILVA, Carina Scandolara da. Abordagem sistêmica com foco na gestão de design sustentável: o caso nuovo design. 2012. 147 f. Dissertação (Mestrado) - Curso de Design e Expressão Gráfica, Design e Expressão Gráfica, Universidade Federal de Santa Catarina, Florianópolis, 2012. Disponível em: <http://www.tede.ufsc.br/teses/PGDE0037-D.pdf>. Acesso em: 26 mar. 2018.

VEZZOLI, Carlo. Design de Sistemas para a sustentabilidade. Salvador: EDUFBA, 2010. 342 p. 